\title{
POSEBNOSTI ISTRE KAO PRIGRANIČNE REGIJE HRVATSKE
}

\author{
Miroslav Sić*
}

\begin{abstract}
Izvleček
$\checkmark$ članku so prikazane posebnosti Istre $v$ regionalnem razvoju Hrvaške. Posebej so izpostavlieni pomen geografskega položaja, gaspodarske razvitosti in razvoja. Regionalna identiteta Istre je analizirana z gospodarskega, kulturnega in političnega vidika. Prikazane so prekomejne funkcije Istre ter tendenca medregionalnega sodelovanja na področju Severnega Jadrana.
\end{abstract}

Ključne besede: regionalne posebnosti, regionalna identiteta, obmejne funkcije, medregionalno sodelovanje, slovensko-hrvaška meja

\section{PARTICULARITIES OF ISTRIA AS A BORDER REGION OF CROATIA}

\begin{abstract}
This paper deals the particularities of Istria in the regional structure of Croatia. The significance of its geographical position, level of economic development, then of its historical development and heritage. The regional identity of Istria is being analysed through three components: economic, political and cultural. The final part of the paper represents the trans-border functions of Istria and tendencies of the interregional cooperation in the area of Sjeverni Jadran (Northern Littoral).
\end{abstract}

Key Words: regional particularities, regional identity, trans- border functions, interregional cooperation.

*Dr., red. prof., Geografski odsjek, PMF, Univerze v Zagrebu, Marulićev trg 19, Zagreb, Hrvatska. 


\section{Uvod}

Suvremeno razdoblje bitno je obilieženo procesom afirmacije regija. Taj se proces odvija na svim razinama, od nacionalne preko kontinentske do globalne. Povezano s njime jača interes za proučavanje regija i javljaju se nove paradigme regionalnog razvitka utemeljene na spoznajama i zakonitostima iz svjetskog kruga.

Afirmacija regija i novi pristupi pitanima regionalnog razvitka logična su posljedica dubokih promjena u ekonomiji, tehnologiii i politici nastalih $u$ posljednjih tridesetak godina. Osobito je značajno svjetsko prerestrukturiranje i globalizacija te deindustrijalizacija i razvoi tercijarnog sektora. Oni su postupno doveli do toga da je fordizam, raniji dominantan model razvoja industrijskih zemalja zamijenjen modelom fleksibilne proizvodnje.

Bivša fordistička proizvodnja - masovna, što dovodi do ekonomije obujma, vertikalno organizirana, s krutom podjelom rada, centraliziranim upravljanjem, velikim poduzećima i komparativnim prednostima, zamijenjuje se sa fleksibilnom specijalizacijom usmjerenom na tehnologiju, završni proizvod, vrhunsku organizaciju i upravljanje. Primat dobivaju raznolikost proizvodnje, horizontalno strukturirani proizvodni sustavi, visokokvalificirani proizvođači, ekonomija dosega, informacijsko umreživanje, istraživanje i razvoj i razvitak tercijarnog gospodarstva.

U uvjetima nove podjele rada, sve veće uloge malih poduzeća i tendencija "grozdanja" takvih poduzeća, ekonomska uspješnost, prije svega, ovisi o suradnji među poduzećima. Uska suradnja među njima ima ključno značenje za fleksibilnu specijalizaciju. Uspiešnost male industrije u "Trećoj Italiji" ili u Južnoj Niemačkoj ne može se objasniti analiziranjem individualnih poduzeća. Nijhova snaga nije u veličini, nego u grozdanju i kooperativnoj konkurentnosti. Radi se o "kolektivnoj efikasnosti" koja omogućava uspješno prilagođavanje brzim gospodarskim promjenama. Tim prije što se takav razvoj potiče lokalnim mjerama ekonomske politike (poduzetništvo, inovativnost, zaposlenost, novi razvojni resursi kao što su znanje, umreživanje i dr.) (S. Maleković, 1995.; J. Padjen, 1997.).

Ti novi razvojni odnosi doveli su do stvaranja novih paradigmi regionalnog razvitka. Ističemo ponajprije paradigmu lokalnog razvitka, koja se pojavila kao posljedica neuspiele politike regionalnog razvoja "odozgo", tj. sa državne razine. Politika regionalnog razvoja vođena sa državne razine najčešće nije 
pridonijela eliminiranju regionalnih dispariteta i riešavanju urbanih problema, nije pospiešila decentralizaciju, niti se suočila s problemom restrukturiranja. Naprotiv, nastojanja na razvitku "odozdo", ti. na lokalnim inicijativama, lokalnim faktorima razvitka i lokalnim resursima dala su pozitivne rezultate i utjecala na brzi i kvalitetniii razvoj lokalnih sredina (S. Maleković, 1995.).

Paradigma regionalnog diferenciranja ili regionalne socijalne interakcije pojavila se $u$ sklopu moderne regionalne geografije zbog potreba razumijevanja kompleksnog karaktera današnjeg visokointeraktivnog globalnog sistema. Za razliku od tradicionalnog koncepta regije, kao homogene i neponovljive prostorne jedinice, koja je odraz adaptacije na prirodnu okolinu tijekom vremena, novi koncept regije definira se kroz socijalne interakcije, odnosno akcije društva. Taj koncept može imati različite pristupe, od političko-ekonomskog preko socijalnog do kulturološkog. No, svima je zajedničko da regiju promatraju kao rezultat regionalnih socijalnih interakcija (M. Vresk, 1997.). Interakcije su uzrok, ali i posliedica socijalnih odnosa između pojedinaca, skupina i institucija u prostoru regije. Ključni element pri tome je proces. On stvara interni homogenizirani prostor i određuje njegov identitet, što dovodi do diferenciranja jedne regije u odnosu na drugu.

Obje paradigme u punoj su mjeri došle do izražaja u suvremenom regionalnom razvoju Europe, posebno u Europskoj uniiji. Pod utjecajem intergracijskih procesa i djelovanja tržišnih zakona, u tom su se prostoru već tijekom 70-ih godina ispoliile krupne razlike između naprednih razvojnih regija i nerazvijenih regija. Da bi se objasnila pojava i našla praktična riešenja primijenjen je model centar-periferija. Postignute spoznaje utjecale su na donošenje politike regionalnog razvoja usmjerene na pomoć regijama koje zaostaju u razvoju. Premda su prvobitne regionalne razlike u 80-im i 90-im godinama smanjene, briga za ravnomjeran regionalni razvoj ostala je i dalje jedna od glavnih preokupacija Europske unije.

U uvjetima dinamičnog razvoja Europske unije posebno značenje dobile su prekogranične regije poznatije pod zajedničkim nazivom euroregije. Broj tih regija s vremenom se povećavao i prostorno širio, iz unutrašnjeg prostora Unije prema njezinim rubovima, u granične zone s tranzicijskim zemljama Srednje-Istočne Europe. Najstarije takve regije ispoljile su izraziti identitet, ponekad mijenjajući svoje funkcije. Bazelska regija na tromeđi Švicarske, Francuske i Niemačke karakteristična je po transgraničnim migracijama prema 
Slika 1: Geografski položaj Istre.

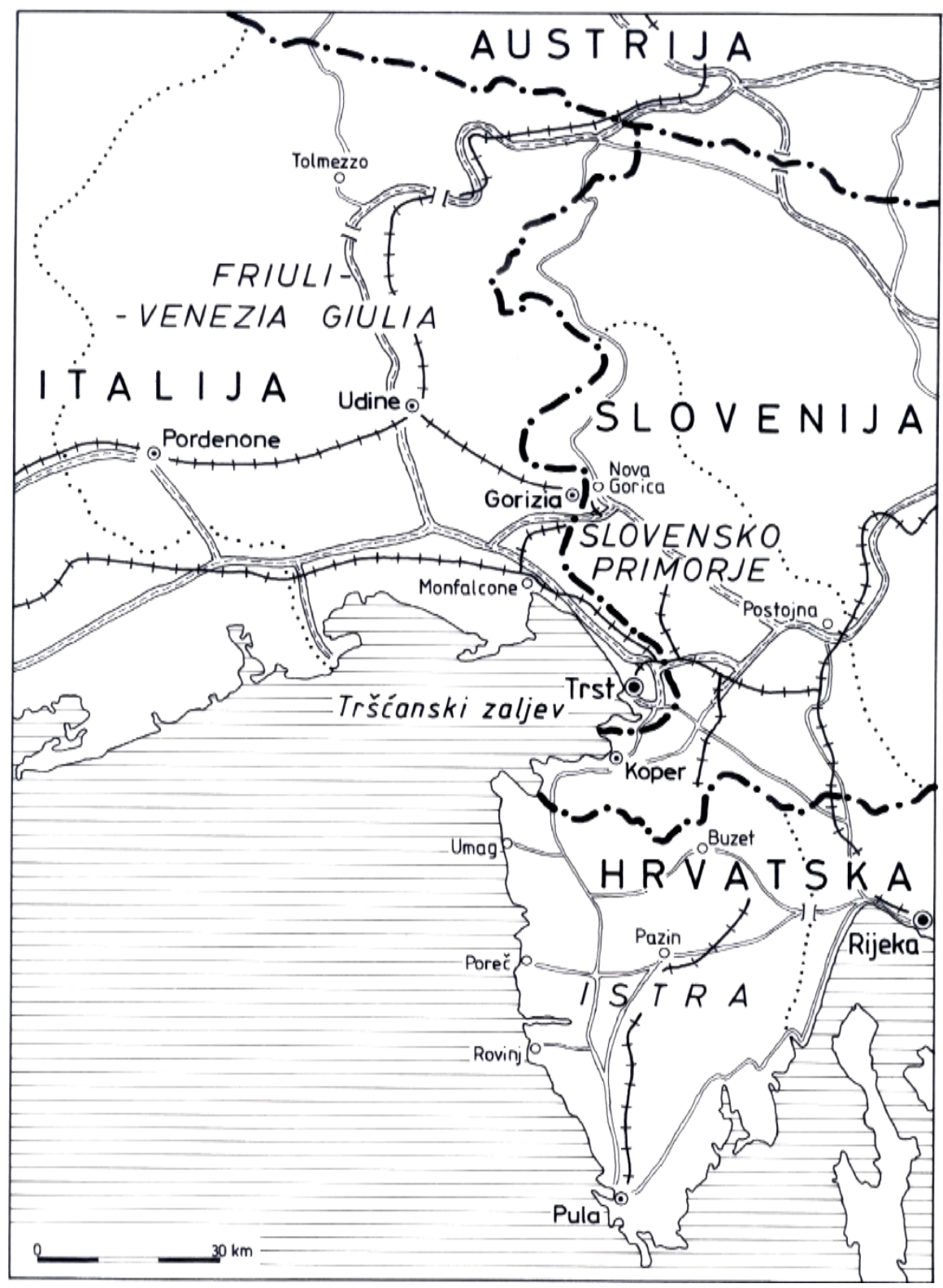


Bazelu, koji, uz to, obavlja i neke uslužne funkcije. Regija Sar-Lor-Lux prvobitno je bila usmjerena na suradnju u bazičnoj industriji, a zatim je kroz restrukturiranje i pod utjecajem krupne infrastrukture prevladala orijentacija na tercijarne funkcije. Poslije 1990. godine pojavile su se prekogranične regije između Niemačke s jedne te Češke i Poljske s druge strane, od Bömerwalda do Pomeranije. $U$ najnovijem periodu, nakon izgradnje mosta između Kopenhagena i Malmö-a, počela se formirati prekogranična Öresund regija, usmierena na "visoki tercijar".

U Hrvatskoj su tijekom devedesetih godina u punoj mjeri došli do izražaja regionalni dispariteti $\mathrm{i}$ odvija se proces regionalne diferencijacije. $U$ tome procesu Istra, promatrana u okvirima istoimene županije, privlači sve veću pažnju. Zajedno sa Zagrebačkom regijom ona ispoljava najveću dinamiku regionalnog razvitka. Posljedica je to njezinih specifičnosti i još više ispoljenih tendencija modernog regionalnog razvoja, što je dovelo do jačanja prekogranične suradnje.

\section{Istra - specifična hrvatska regija}

Za Istru se s razlogom može reći da predstavlia specifičnu hrvatsku regiju. Regionalna specifičnost Istre određena je njezinim geografskim položajem, relativno visokim stupnjem ekonomske razvijenosti, prirodnim i pejsažnim raznolikostima i pogodnostima te povijesnim razvojem i nasljeđem.

S obzirom na geografski položaj, Istra je prigranična i, u odnosu na regiju centra, periferna regija Hrvatske. Na značenje prigraničnog položaja bitno utječe činjenica da se istarski prostor nalazi na području kontakta Hrvatske, Slovenije i Italije. Istra je, prema tome, regija na tromeđi. Ona se izravno povezuje sa susjednim slovenskim i talijanskim regijama, a u povoljnim je prostornim odnosima i sa srednjeeuropskim zaleđem. Kako se radi o razvijenim sredinama i zajednicama, interakcija s njima ujtecala je na brži gospodarski razvoj istarskog prostora.

Druga značajka geografskog položaja, periferni položaj Istre u odnosu na Zagrebačku regiiu, ima relativno značenje. Zbog specifičnog oblika Hrvatske, perifernost, prvenstveno prostorna, a najčešće i funkcionalna, izrazita je kod više hrvatskih regija. Ključno pitanje koje se pri tome postavlja je prometno povezivanje. To je slučaj i kod Istre, koja zbog neadekvatne povezanosti s regijom centra, nije dovolino integrirana u nacionalni prostor. Međutim, 
ta perifernost nije omela njezin brži ekonomski i ukupni razvoj, što ukazuje na značenje kako internih, tako još više eksternih razvojnih faktora.

Istra je razvijena hrvatska regija. Jasno se to razabire iz određenih ekonomsko-socijalnih pokazatelja. Na relativno rijetko naseljenom prostoru, koji okuplja nešło preko 200.000 stanovnika, od čega oko 54\% živi u gradovima, izrazita je dinamika gospodarske aktivnosti. Osobito u odnosu na ostale razvijene regije, odnosno županije. Istra ima najveću gustoću poslovnih subjekata, najviše relativne investicije i najnižu stopu nezaposlenosti. U uvjetima kada državna statistika ne daje podatke o županijskim bruto društvenim proizvodima po stanovniku (GDP), ovo su, nesumnjivo, reprezentativni i, uz to, vrlo indikativni pokazatelji ekonomske razvijenosti Istre. Dodatni indikatori njezine razvijenosti jesu stupani automobilizacije i gustoća telefonske mreže (Tab. 1.). S takvim obiliežjima Istarska se županija mjeri sa gradom Zagrebom i Zagrebačkom županijom, odnosno Istra je poslije regije centra najrazvijenija hrvatska regija.

I neki drugi elementi ukazuju na regionalne specifičnosti Istre. Ističemo njezine prirodne i pejsažne raznolikosti i pogodnosti. Fizionomski je Istra posebna geografska cjelina, kako zbog svog poluotočnog karaktera, tako još više radi reljefnih i ukupnih prirodnogeografskih obilježja. $U$ reljefu dominiraju niski vapnenački prostori zapadne i južne Istre i unutrašnja flišna zona, dok je uski i meridionalni gorski okvir odvojio istarski prostor od istočnijeg zaleđa. Maritimnost i povoljna klima, osobito u priobalnoj zoni, prevlast nizinskog reljefa te bogatstvo voda i raširenost plodnih tala, napose crvenice, imali su za posljedicu trajnu ekološku privlačnost istarskog prostora.

Prirodnim pogodnostima treba pridodati pejsažne vrijednosti Istre. Dugotrajna naseljenost, koja je prošla kroz više civilizaciiskih ciklusa, ostavila je brojne društvene sadržaje, često velike kulturne vrijednosti. Oni su uklopljeni u konkretnu prirodnu sredinu, prilagodili se toj sredini i obogatili je svojim vrijednostima. Sklad pejsaža, u kojem se prožimaju prirodni elementi i kulturni sadržaji, nesumnjivo je specifičnost istarskog prostora.

Istra se ističe i specifičnim povijesnim razvojem i naslieđem. Kroz dugo vremensko razdoblje ona se nalazi na razmeđi velikih političkih sila i kulturnih krugova, što se odrazilo na njezinom teritorijalno-političkom razvitku, složenoj etničkoj strukturi i raznovrsnim kulturno-povijesnim sadržajima. Geopolitičke su promjene bile naročito značajne tijekom 20. stoljeća, kada se izmjenjuju austrijski, talijanski i jugoslavenski, odnosno hrvatski period. Povezano s time, 
Istra ima najmlađe granice u Hrvatskoj. I pored tako složenog razvoja, ona je uspiela sačuvati duboke hrvatske korijene i razviti istovremeno sklonost i otvorenost ka multikulturi. Bogatstvo kulturno-povijesnog nasljeđa i multikulturne značajke pozitivni su i poticajni elementi za suvremeni regionalni razvoj Istre.

\section{Regija sve izraženijeg identiteta}

Istra se u okvirima Hrvatske ne ističe samo po svojim specifičnim geografskim i ostalim obilježjima, već i po razvojnim tendencijama koje dovode do izgradnje vlastitog identiteta - političkog, ekonomskog i kulturnog. Najizrazitiji je kulturni identitet, sve važniji postaje ekonomski, dok je politički u procesu oblikovanja. Kraća analiza istaći će bitne značajke svakog od navedenih identiteta.

Kulturni identitet Istre određuju dvije komponente: 1. kulturno nasljeđe i 2. suvremene kulturne funkcije. Razvijajući se na dodiru dviju velikih civilizacijskih i kulturnih sredina Mediterana i Srednje Europe, Istra je postala prostor bogat arhitektonskim i spomeničkim sadržajima, likovnim vrijednostima i ostalim kulturno-civilizacijskim dostignućima. Prožimanje graditeljskog naslieđa, urbanog, ali i ruralnog, je takvo da se s pravom ističe da istarski prostor ima identitet ambijenta (B. Iskra, 1992.). Povezane s takvim nasljeđem su suvremene kulturne funkcije. S obzirom na svoju površinu i broj stanovnika, Istra ima najveću koncentraciju kulturnih manifestacija (filmski festivali, glazbene večeri, literarni i folklorni skupovi i dr.). One su u velikoj mjeri u funkciii razvoja turizma, ali su kao elemant identiteta istovremeno poticajni faktor ukupnog i skladnog regionalog razvitka s obzirom da se, pored priobalja, odvijaju i u unutrašnjem dijelu istarskog prostora.

Ekonomski identitet Istre određuje, prije svega, orijentacija na turizam. U turističkom razvoju Hrvatske Istra ima dominantnu ulogu - 1998. godine na nju je otpalo $40 \%$ od ukupnog broja noćenja. Turizam je do sada bio jedna od najpropulzivnijih djelatnosti i normalno je da će on to i dalje ostati, premda je sada na svojevrsnoi prekretnici. Nakon tri decenija ekspanzije (1960.1990.) zasnovane pretežno na komparativnim prednostima i poticane "odozgo","što je dovelo do izgradnje velike turističke infrastrukture (hotelska naselja, apartmani, kampovi, privatni smieštaj) i odrazilo se na značajnim ekonomskim efektima, a u prostornom pogledu na tendencijama litoralizacije (M. Vresk, 1987.), nameće se potreba nove razvojne orijentacije turizma. 
S obzirom na svoju ponudu, on mora biti još raznovrsniji, od prestižnog turizma Brijuna, preko klasničnog masovnog turizma, u kojem bi sve veću ulogu trebali imati obiteljski komercijalni objekti, do oblika alternativnog turizma (agroturizam, vinske ceste, biciklističke staze i dr.) koji istovremeno omogućava turistički razvoj ranije zapostavljene unutrašnje Istre. Takav turizam mora biti istovremeno i ekološki utemelien, "mekan", kako bi omogućio održivi razvoj i treba poticati razvoi povezanih resursa, osobito određenih segmenata poljodjelstva, stočarstva i ribarstva.

Spomenute su gospodarske djelatnosti u razdobliu "turističke groznice" i polarizacije prema obalnim centrima bile uglavnom zapostavljene, premda imaju sve uvjete razvoja, od tradicije preko povolinih prirodnih uvjeta i ekoloških pogodnosti do velike potražnje na licu miesta. Izuzetak u pozitivnom smislu je samo razvoj vinogradarstva koje se uklopilo u turističko usmjerenje, kao privlačan element ponude i postalo dodatni gospodarski identitet Istre.

Izvan turizma i određenih segmenata primarnog sektora, oblikuje se gospodarski identitet osnovan na proizvodnim i servisnim dielatnostima. Ne radi se tu o tradicionalnoj industriji (brodogradnja, cementna i prehrambena industrija) i o industriji stvorenoj u fazi aktiviranja unutrašnje Istre (automobilska, tekstilna $\mathrm{i}$ dr.), niti o klasičnoj trgovini. Nove tendencije u ovim djelatnostima vidljive su na pojavi sitnih proizvodnih pogona potrošačke industrije, redovito povezanih sa trgovinom, u sklopu malog i srednjeg poduzetništva. Aktiviraju se poduzeća koja su u velikoj mjeri vezana uz gospodarski prostor Italije, posebno bližih talijanskih pokrajina i koja imaju posredničku ulogu u snabdjevanju određenim robama šireg hrvatskog tržišta.

Politički identitet tek je u početnoj fazi izgradnje, ali nesumnjivo jača, među ostalim i pod utjecajem spoznaja o učincima afirmacije regija u okviru Europske unije. U toj je sredini, naime, sve prisutnija težnja regija da se ublaži utjecaj političkih odluka centralnih, odnosno supranacionalnih vlasti. Tvrdi se da lokalne i regionalne vlasti imaju bolii uvid u probleme regija i bolii pregled nad sredstvima. Osnovu čini, dakle, pomak odlučivanja prema regionalno manjim jedinicama i prema većoj fiskalnoj autonomiji.

Novije buđenje političke svijesti u Istri očekivana je i razumljiva pojava, pogotovo u odnosu na prilike u bivšoj SFRJ, gdje su strukture odlučivanja bile hijerarhijske i veoma krute. $U$ novim uvjetima ističe se uloga vlastitih snaga i "endogenih" potencijala te kompleksno iskorištavanje resursa i inovacija. Politički identitet Istre, koji je tek u fazi izgradnje, morao bi se sastojati u 
samostalnom oblikovanju politike razvitka, usklađenom s razvojnom politikom Hrvatske i u poticanju uspostavlianja surdnje s drugim regijama u Hrvatskoj i izvan nje (S. Švaljek, 1995.).

Regionalni identitet Istre, sa svoja tri karakteristična segmenta, u novim uvjetima sve više dolazi do izražaja i pozitivno utječe na njezin suvremeni razvoj. Osobito na razvitak prekograničnih funkcija, što je predmet posljednjeg poglavlja ovoga rada.

\section{Regija prekograničnih funkcija}

U regionalnoj strukturi Hrvatske Istra se, pored prethodno navedenih regionalnih specifičnosti i sve izrazitijeg regionalnog identiteta, posebno ističe svojim prekograničnim funkcijama. Ni jedna regija u Hrvatskoj nije u tolikoj mjeri i tako kompleksno orijentirana na ekonomske i ostale veze sa regijama susjednih država. Povezano s time, nema regije u Hrvatskoj koja se u tolikoj mjeri približila integriranoj Europi kao što je to slučaj sa Istrom.

Koji su sve čimbenici utjecali na razvoi prekograničnih funkcija Istre? Ponajprije, to je postojanje relativno otvorene granice prema Italiji i Austriji već u periodu bivše Jugoslavije. Prekogranične veze počinju se stvarati i jačati od 1965. godina dalje, kada dolazi do jačeg otvaranja tadašnje države prema zapadnim zemljama. U takvim je uvjetima sve više rasla privlačnost Trsta, koji od prije ima tradiciju glavnog trgovačko-poslovnog središta istarskog prostora. No, tijekom narednih decenija javili su se i dodatni elementi privlačnosti susjednih područja Italije, prije svega, pokrajine Friuli-Venezia Giulia, a također i Veneta, koje razvijaju modernu ekonomsku strukturu i doživljavaju dinamičan razvoj. Susjedna regija Slovenskog Primorja također je utjecala na jačanje međuragionalne, odnosno poslije 1990. prekogranične suradnje. Razvijajući kompleksnu litoralnu ekonomiju, Koper zajedno s ostalim primorskim centrima postaje, uz Trst, sekundarno polarizacijsko žarište, osobito za sjeverni dio Istre. Nepravilna horizontalna struktura urbanog sistema istarskog prostora, sa periferno položenom Pulom, dodatno je stimulirala takve veze. Tim prije što je izgradnjom autocesta u susjednim područjima Italije $\mathrm{i}$ Slovenije Istra postala znatno dostupnija. S razvojem prekograničnih veza prirodno povoljna i pejsažom atraktivna Istra s vremenom je sve više privlačila, a njezino turističko usmjerenje postalo je komparativna prednost, osobito u odnosu na gusto naseljeni pojas Trst-Venecija i skučeni prostor užeg 
Slovenskog Primorja. ističemo na kraju da su prekograničnu suradnju stimulirala i socijalna obilježja istarskog stanovništva, osobito otvorenost i sklonost ka multikulturi, a značajna je i uloga optanata koji su nakon drugog svjetskog rata iselili iz Istre, ali su s njom ostali trajno povezani.

Za pobliže upoznavanje prekograničnih funkcija Istre potrebno je ukazati na glavne pravce prekograničnog povezivanja i na strukturu niihovih tokova. Naijače veze Istra održava sa susjednim regijama Friuli-Venezia Giulia i Slovensko Primorje. Struktura prekograničnih tokova sa njima je složena i oni se odvijaju recipročno. Na temelju saznanja iz različitih izvora (objavljeni rezultati anketa, informaciie iz štampe, intervjui) može se reći da su u strukturi prekograničnih tokova iz pokrajine Friuli-Venezia Giulia najviše zastuplieni vikendni i sezonski turizam, zatim kapital, različite robe te utjecaji povezani s polarizacijskom ulogom Trsta. U suprotnom smjeru na prvom je mjestu kupovina, a zatim dolaze tokovi u vezi sa zaposlenjem, trgovinom i pojedinim uslugama (SI. 2.).

Slika 2: Struktura prekograničnih ekonomskih tokova između Istre, Slovenskog Primoria i Friuli-Venezia Giulia-e.

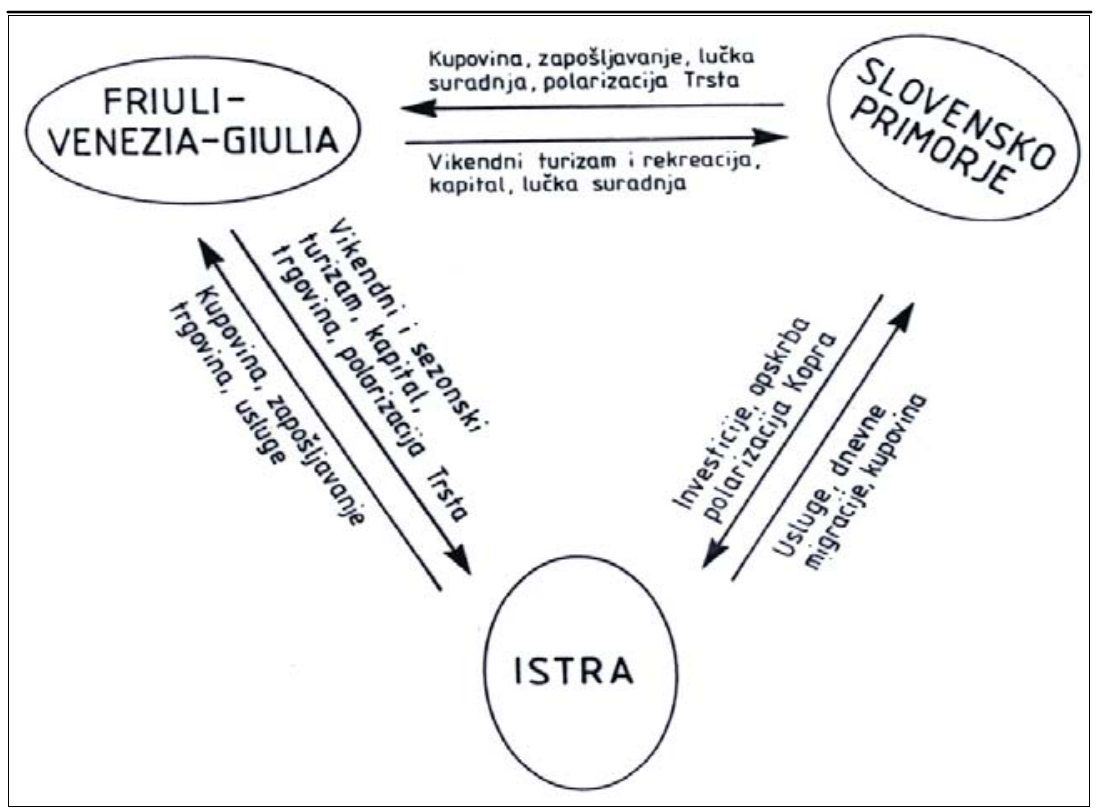


Veze Istre sa Slovenskim Primorjem manje su intenzivne i raznovrsne. Ističu se, pri tome, tokovi utjecani kupovinom i zaposlenjem, koje je u novije vrijeme donekle smanjeno. Iz Slovenskog primoria prema Istri odvijaju se značajna turistička kretanja, a vidljiv je i utjecaj dislociranih poduzeća koja djeluju u prostoru Istre (Autobusni promet "Slavnik", mreža banzinskih postaja Istra Benz/Mol, pojedini industrijski pogoni). Slično Trstu, samo u manjoi mjeri, Koper (zajedno sa susjednim centrima) obavlja funkciju polarizacijskog centra; njegov se utjecaj jače osjeća u sjevernom dijelu Istre.

I u radovima pojedinih talijanskih i slovenskih autora (A. Bianchetti, 1996.; M. Bufon, 1993a, 1993b) istaknuto je značenje prigraničnog i mosnog položaja pokrajina Friuli-Venezia Giulia i Slovenskog Primoria, što se odrazilo na razvoju šire prekogranične suradnje. Međusobne veze tih dviju regija ukazuju, slično kao u slučaju Istre, na značenje trgovinskih i turističkih tokova. Iz svega navedenog proizlazi da se na hrvatsko-slovensko-talijanskoj tromeđi odvija intenzivna i recipročna gospodarska suradnja. Model te trojne suradnje, obilježen odgovarajućim ekonomksim tokovima, prikazan je na slici 2.

U uvjetima sve veće afirmacije regija u Europi, unutar Europske unije i u kontaktnim zonama prema tranziciiskim zemljama, došle su do izražaja određene tendencije i inicijative institucionalnog povezivanja regija i na hrvatsko-slovensko-talijanskoj granici te se govori o području ili euroregiij Sjeverni Jadran. Te se inicijative oslanjaju na službenu politiku Europske unije i polaze od dosadašnje međuregionalne suradnje kao i od određenih gospodarskih, prometnih, ekoloških, kulturnih i drugih pitanja koja bi trebalo riešavati kroz zajedničku strategiju prostornog planiranja i razvoja. Spomenute su inicijative otvorile istovremeno brojne dileme i traže odgovore na neka važna pitanja uspješnog, ali i prihvatljivog međuregionalnog razvoja na širem prostoru Sjevernog Jadrana.

\section{Litertura}

Bianchetti A.., 1996.: Friuli-Venezia Giulia: Problems and Prospects of a Central European Border and Bridge Region in the Process of European Intergration, $U$ "Central Europe after the Fall of the Iron Curtain", Wiener Osteuropa Studien, Bd. 4, str. 189.-215. 
Bufon M., 1993a: Cultural and Social Dimensions of Borderlands: The Case of the Italo-Slovene Trans-border Area. GeoJournal, 30, (3) str. 235.-240.

Gelo J., 1999.: Ratni učinci na promjene demografskih struktura u Hrvatskoj, Društvena istraživanja, 8 (5-6), str. 735.-749.

Iskra B.,1992.: Analiza elemenata urbane i arhitektonske kompozicije istarskog prostora i teze o specifičnom identitetu ambijenta u kontekstu prostornog povijesnog kontinuiteta istarske regije. Gospodarstvo Istre, 1, str. 87.-91.

Maleković S., 1995.: Novi pristup razvitku Istre. Ekonomski pregled, 46, (3-4) str. 318-327.

Padjen J., 1995.: Istra, njezin razvitak i položaj u Hrvatskoj. Ekonomski pregled, 46(3-4) str. 213.-223.

Padjen J., 1997.: Novi procesi regionalnog razvitka. Ekonomski pregled 48(1) str. 75.-80.

Sić M., 1996.: Prometni sustav i regionalni razvoj Hrvatske. Zbornik radova I. Hrvatskog geografskog kongresa, Zagreb, str. 93.-101.

Švaliek S., 1995.: Regionalni identitet Istre. Ekonomski pregled, 46 (3-4) str. 253.-262.

Vresk M., 1987.: Polarizacijski efekti urbanizacije Istre. Radovi Geografskog odjela, 22, str. 43.-53.

Vresk M. 1997.: Regionalna geografija danas. Acta Geographica Croatica, 32, str. 69.-82.

\section{PARTICULARITIES OF ISTRIA AS A BORDER REGION OF CROATIA}

\section{Summary}

During the nineties, regional disparities became prominent in Croatia, and the process of regional differentiation was intensified. In that process Istria, observed in the framework of the county with the same name, draws more and more attention. Together with the Zagreb region, it shows the greatest dynamics of regional development. Three aspects are important for getting acquainted with the modern regional development of Istria: its geographical and other particularities, more and more prominent identity and trans-border function development. Geographical particularities of Istria are the consequence of its 
position at the three-border point of Croatia, Slovenia and Italy, and also of its peripheral position in relation to the region of the centre of Croatia. But, its peninsular character is also significant as well as its heterogenous and attractive natural basis. Furthermore, Istria is a developed region of Croatia. This can be seen out of some relevant socioeconomic indicators (density of business subjects, realized investments, share of unemployed population, motorization level). By the level of the achieved economic development, Istria lags only behind the Zagreb region. It is also remarkable for its specific historical development and heritage.

Relative to the other Croatian regions, the Istrian region shows the most prominent regional identity. The most significant is the cultural identity noticeable in the rich cultural heritage and modern cultural functions. Both components are included in the tourist offer of Istria. More recently, the economic identity becomes more and more important. it is primarily determined by the prevailing direction towards tourism as the main and most promising branch of economy. But some accompanying activities of the primary sector such as wine-growing, are also the elements of the economic identity. But the economic identity is more and more influenced by the production-trading activities, development in the framework of medium and small business. on the one hand, they are linked to the business cooperation with the neighbouring regions, especially in Italy, and on the other, to the wider Croatian market. The political identity is still at the stage of formation. Essentially, it should form the policy of its own development adjusted with the Croatia development policies, and stimulate cooperation with other regions.

With the more recent development Istria has become a region of transborder functions. It is the consequence of its position on the contact of the neighbouring countries, developed environments, then of the open border tradition, traffic accessibility, comparative advantages in economic development, natural privileges, cultural heritage, and the tendency of the Istrian environment towards multiculture. The most intensive trans-border connections are those with the regions Friuli - Venezia Giulia and Slovensko primorie (Slovenian Littoral). They are complex and reciprocal. The flows connected with employment and shopping dominate from Istria towards the mentioned regions, and in the opposite direction there are most often tourist flows, on weekends and seasonally, then trading flows and connections under the influence of the polarization importance of Trieste and Koper. There are 
also intensive trans-border connections between Friuli - Venezia Giulia and Slovensko primorje (Slovenian Littoral), so we can talk about a three-sided interregional cooperation. Its model is shown on the figure 2 .

The noticeable tendencies of the economic connection and wider interregional cooperation of the regions on the Croatian-Slovenian-Italian three-border point have driven up to certain initiatives and projects with the purpose of figuring out a common strategy of regional development and planning, and, at the further stage, of establishing the complete euroregion. Simultaneously, the mentioned initiatives brought about numerous dilemmas and are looking for the answers on some important questions about further development of the interregional relations in a wider area of Sieverni Jadran (Northern Adriatic). 